\title{
Modified PZT ceramics as a material that can be used in micromechatronics ${ }^{\star}$
}

\author{
Radosław Zachariasz ${ }^{\mathrm{a}}$ and Dariusz Bochenek \\ University of Silesia, Institute of Technology and Mechatronics, 12, Żytnia St., Sosnowiec 41-200, Poland
}

Received 26 May 2015 / Received in final form 25 August 2015

Published online 11 November 2015

(C) The Author(s) 2015. This article is published with open access at Springerlink.com

\begin{abstract}
Results on investigations of the PZT type ceramics with the following chemical composition: $\mathrm{Pb}_{0.94} \mathrm{Sr}_{0.06}\left(\mathrm{Zr}_{0.50} \mathrm{Ti}_{0.50}\right)_{0.99} \mathrm{Cr}_{0.01} \mathrm{O}_{3}$ (PSZTC) which belongs to a group of multicomponent ceramic materials obtained on basis of the PZT type solid solution, are presented in this work. Ceramics PSZTC was obtained by a free sintering method under the following conditions: $T_{\text {sint }}=1250{ }^{\circ} \mathrm{C}$ and $t_{\text {sint }}=2 \mathrm{~h}$. Ceramic compacts of specimens for the sintering process were made from the ceramic mass consisting of a mixture of the synthesized PSZTC powder and 3\% polyvinyl alcohol while wet. The PSZTC ceramic specimens were subjected to poling by two methods: low temperature and high temperature. On the basis of the examinations made it has been found that the ceramics obtained belongs to ferroelectric-hard materials and that is why it may be used to build resonators, filters and ultrasonic transducers.
\end{abstract}

\section{Introduction}

A possibility to use a piezoelectric ceramics in the electronic industry, in micromechatronics [1], electroacoustics or to build elements of medical equipment is conditioned mainly by stability of its mechanical and electric parameters $[2-5]$. One of the most interesting materials for use in micromechatronics is a multicomponent solid solution PZT-type with perovskite structure [6-9]. Optimization of a technological process, a selection of the $\mathrm{PbTiO}_{3}$ concentrations (in the solid solution of a PZT type) and also a modification of the basic chemical composition with appropriate admixtures have a significant influence on stability of piezoelectric transducer operating $[10,11]$.

An aim of this work was to obtain and examine basic parameters of a multicomponent PZT type ceramics admixed with chromium regarding a possibility of its use in electroacoustics. Electrical permittivity $\left(\varepsilon_{33} / \varepsilon_{0}\right)$, a tangent of the dielectric loss angle $(\tan \delta)$, a coefficient of the electromechanical coupling, mechanical quality factor, temperature stability of a resonance frequency $\Delta f_{r} / f_{r}$, mechanical losses $Q^{-1}$ and a value of the Young modulus $Y$ belong to a set of basic parameters which decide about ceramics usability for a given type of applications.

\section{Experiment}

A test material was a PZT type ceramics with the composition of $\mathrm{Pb}_{0.94} \mathrm{Sr}_{0.06}\left(\mathrm{Zr}_{0.50} \mathrm{Ti}_{0.50}\right)_{0.99} \mathrm{Cr}_{0.01} \mathrm{O}_{3}$ (in the

\footnotetext{
* Contribution to the Topical Issue "Materials for Dielectric Applications" edited by Maciej Jaroszewski and Sabu Thomas.

${ }^{a}$ e-mail: radoslaw.zachariasz@us.edu.pl
}

work designated as PSZTC), which is included into a group of ferroelectrically hard materials. The powder mixture components were milled using planetary mill FRITSCH Pulwerisette 6 , in ethanol, by $12 \mathrm{~h}$. Next the powder was sintered freely at the temperature of $T_{\text {sint }}=$ $1250{ }^{\circ} \mathrm{C}$ for $t_{\text {sint }}=2 \mathrm{~h}$. After making of compacts of the forms required on the hydraulic press, they were subjected to drying in the air atmosphere for $24 \mathrm{~h}$. The compacts prepared in such a way were placed in the ceramic crucible and they were sintered in the pad of $\mathrm{PbO}$ and $\mathrm{ZrO}_{2}$ mixture. After completion of the technological process the ceramic PSZTC specimens were subjected to a mechanical treatment (grinding and polishing), in order to prepare their surfaces properly for putting electrodes by a silver paste burning method.

The PSZTC specimens were subjected to a poling process by two poling methods. In the low temperature method (high voltage method) the PSZTC ceramics was polarized in the silicon oil medium under the following conditions: poling field $E_{\text {pol }}=40 \mathrm{kV} / \mathrm{cm}$, poling temperature $T_{\text {pol }}=165{ }^{\circ} \mathrm{C}$ and poling time $t_{\text {pol }}=0.5 \mathrm{~h}$. In the second high temperature poling method (low voltage method) the poling was conducted in the air atmosphere, using an impulse application of the electric field. The following poling conditions were used: poling temperature $T_{\text {pol }}=360{ }^{\circ} \mathrm{C}$ while the poling field applied by impulses $E_{\text {pol }}=17 \mathrm{kV} / \mathrm{cm}$ (six cycles lasting for $t_{\text {pol }}=15 \mathrm{~s} \mathrm{each}$ ).

After completing the poling process of the PSZTC ceramics, its structural, dielectric, mechanical, piezoelectric parameters and parameters of resonance stability were tested. The microstructure examinations were made by a SEM scanning microscope HITACHI S-4700. Measurements of the $Q^{-1}(T)$ internal friction and the Young 


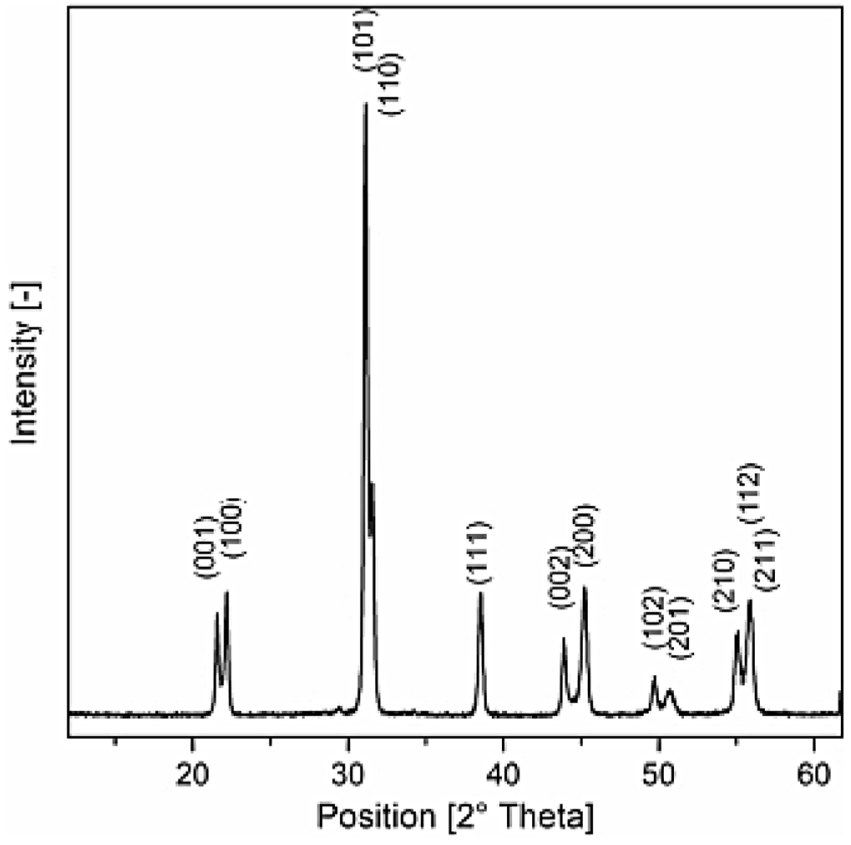

Fig. 1. X-ray diffraction pattern of the PSZTC ceramics.

modulus $E(T)$ were made by an relaxator of acoustic frequencies of a RAK-3 type, dielectric measurements were performed on a capacity bridge of a QuadTech 1920 Precision LCR Meter type, at different frequency of the measurement field (from $100 \mathrm{~Hz}$ to $20 \mathrm{kHz}$ ) and whereas an examination of the hysteresis loop was carried out using the Matsusada Inc. Heops-5B6 precision high voltage amplifier. The number of specimens subjected to examination was 3 .

\section{Results and discussion}

The X-ray examinations (Fig. 1) of ceramics $\mathrm{Pb}_{0.94} \mathrm{Sr}_{0.06}\left(\mathrm{Zr}_{0.50} \mathrm{Ti}_{0.50}\right)_{0.99} \mathrm{Cr}_{0.01} \mathrm{O}_{3}$ have shown, that at room temperature $T_{r}$ it has a perovskite type structure with a tetragonal phase near the morphtotropic area $\left(a=4.075 \AA, c=4.099 \AA, \delta_{T}=1.1 \%\right)$ without the presence of foreign phases (pirochlore phase). The PSZTC ceramics has density of $\rho_{e k s p}=7.23 \mathrm{~g} / \mathrm{cm}^{3}$.

The PSZTC ceramics microstructure image (Fig. 2) is characterized by a fine grained nonporous structure with a densely packed and tight sintered structure as well as inhomogeneous grain. The average size of the PSZTC ceramics is lower than $\bar{r}<2.0 \mu \mathrm{m}$.

Internal friction measurements for the PSZTC ceramic specimens were conducted in the temperature range from $25^{\circ} \mathrm{C}$ to $380{ }^{\circ} \mathrm{C}$, for three different heating rates $(1$, $3,5 \mathrm{deg} / \mathrm{min})$. The $Q^{-1}(T)$ and $E(T)$ temperature dependences obtained for the PSZTC ceramics are presented in Figure 3.

A characteristic $\mathrm{P}_{\mathrm{F}}$ maximum was observed on the $Q^{-1}(T)$ curve and a $\mathrm{M}_{\mathrm{F}}$ minimum accompanying it, connected with a ferroelectric-paraelectric phase transition,
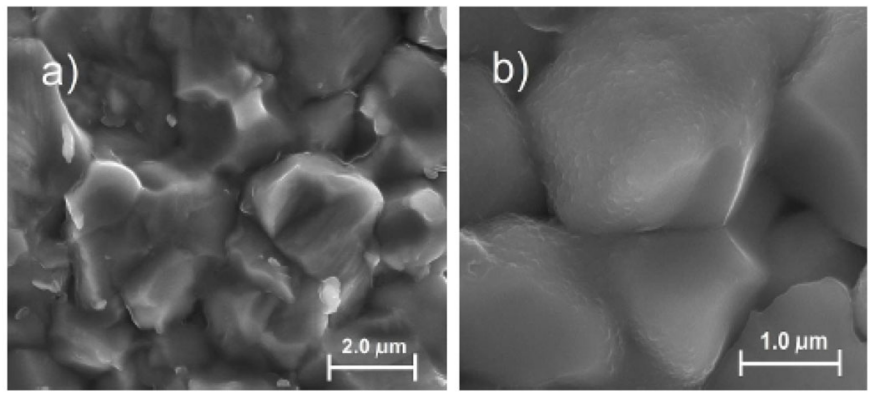

Fig. 2. SEM photographs of a fracture microstructure of PSZTC ceramics, (a) magnify $\times 15$, (b) $\times 30$.

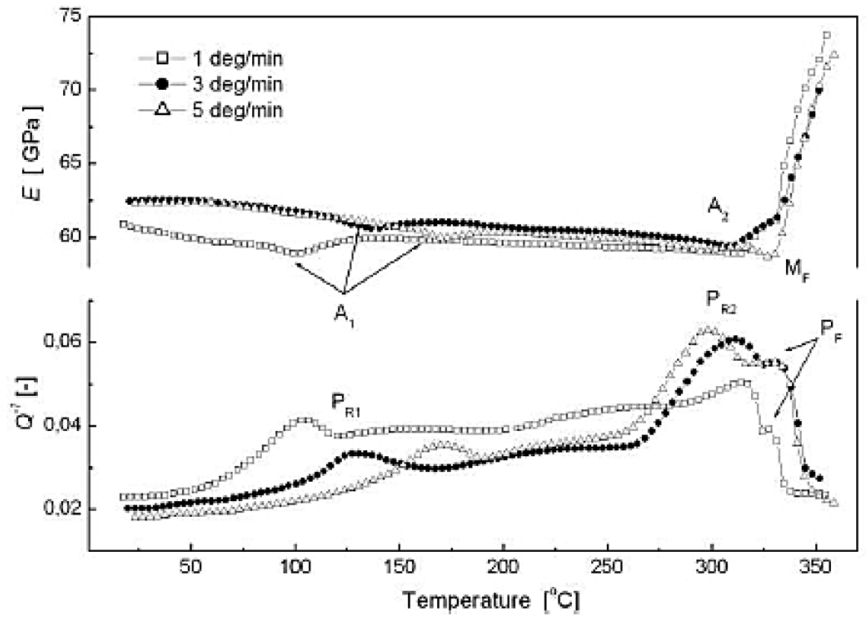

Fig. 3. Temperature dependences of the $Q^{-1}(T)$ and $E(T)$ obtained for the PSZTC ceramics.

was observed on the $E(T)$ curve. Peaks $\mathrm{P}_{\mathrm{R} 1}$ and $\mathrm{P}_{\mathrm{R} 2}$ observed on the $Q^{-1}(T)$ curve and anomalies connected with them on the Young modulus curve, marked as minima $\mathrm{A}_{1}$ and $\mathrm{A}_{2}$ showed a relaxation character, when their temperature position depended on the specimen heating rate. On the basis of the Arrhenius law [12] which deals with processes activated thermally, the relaxation time and an activation energy $H$ were determined. The activation parameters of the $\mathrm{P}_{\mathrm{R} 1}$ peak $\left(H=1.11 \mathrm{eV}, \tau_{0}=2.18 \times 10^{-15}\right)$ point out to a process connected with mutual influence of point defects and domain walls (mainly $90^{\circ}$ ) [13]. The activation parameters of the $\mathrm{P}_{\mathrm{R} 2}$ peak $(H=2.35 \mathrm{eV}$, $\tau_{0}=1.55 \times 10^{-24}$ ) obtained suggests that the $\mathrm{P}_{\mathrm{R} 2}$ peak may be connected with a more complex process. As it was shown in work [13], the $\mathrm{P}_{\mathrm{R} 2}$ depended on a few parameters for example: a rate of temperature transition or a concentration of oxygen vacancies. The fact that the $\mathrm{P}_{\mathrm{R} 2}$ peak is near the $\mathrm{P}_{\mathrm{F}}$, peak connected with the ferroelectricparaelectric phase transition, suggests instability in the domain wall arrangement.

Temperature dependences of the electric permittivity are presented in Figure 4. The PSZTC ceramics has a phase transition from a ferroelectric phase to paraelectric one at $T_{C}=360{ }^{\circ} \mathrm{C}$ temperature and high values of electric permittivity. Low values of the dielectric losses for the PSZTC material (Tab. 1), maintain to the temperature of 


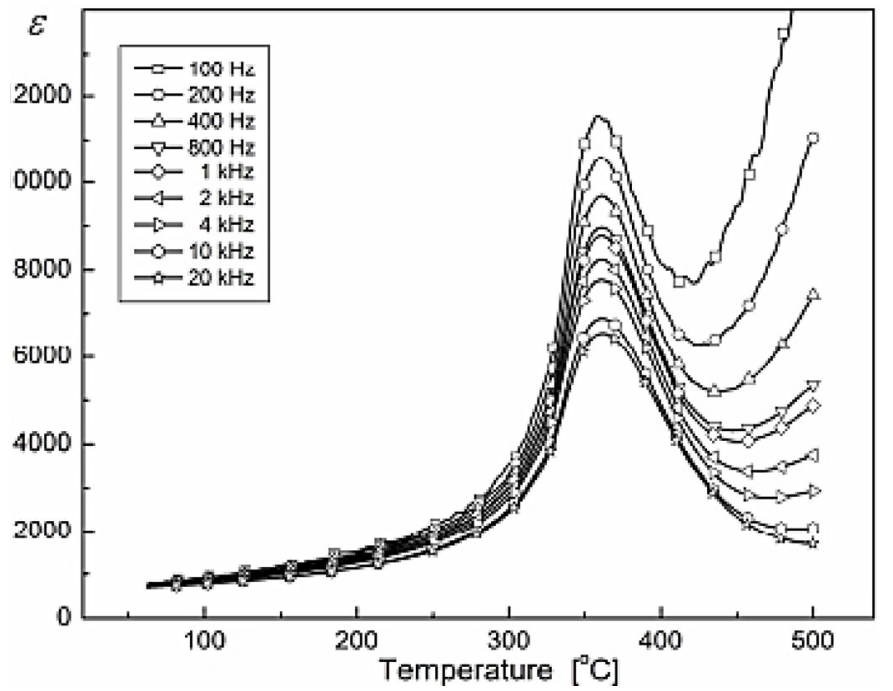

Fig. 4. Plot of dependences of the electric permittivity in the temperature function for a cooling cycle for the PSZTC ceramics.

Table 1. An influence of the poling method on the piezoelectric parameters of the PSZTC ceramics.

\begin{tabular}{|c|c|c|}
\hline & $\begin{array}{c}\text { Low temperature } \\
\text { method }\end{array}$ & $\begin{array}{l}\text { High temperature } \\
\text { method }\end{array}$ \\
\hline$\overline{E_{\mathrm{pol}}[\mathrm{kV} / \mathrm{cm}]}$ & 40 & 17 \\
\hline$t_{\mathrm{pol}}$ & $15 \mathrm{~min}$ & $15 \mathrm{~s}$ \\
\hline$T_{\mathrm{pol}}\left[{ }^{\circ} \mathrm{C}\right]$ & 165 & 360 \\
\hline$n$ (number of impulse) & - & 6 \\
\hline$\rho_{e k s p}\left[\mathrm{~kg} / \mathrm{m}^{3}\right]$ & \multicolumn{2}{|c|}{7.23} \\
\hline$f_{a} / f_{r}$ & 1.072 & 1.054 \\
\hline$\varepsilon_{33}^{T} / \varepsilon_{0}$ at $T_{r}$ & 800 & 810 \\
\hline $\tan \delta$ at $T_{r}$ & 0.0076 & 0.0074 \\
\hline$k_{p}$ & 0.41 & 0.36 \\
\hline$d_{31} \times 10^{-12}[\mathrm{C} / \mathrm{N}]$ & 68 & 63 \\
\hline$S_{11}^{E} \times 10^{-13}\left[\mathrm{~m}^{2} / \mathrm{N}\right]$ & 112 & 118 \\
\hline$V_{r}[\mathrm{~m} / \mathrm{s}]$ & 2197 & 2153 \\
\hline$g_{31} \times 10^{-3}[\mathrm{Vm} / \mathrm{N}]$ & 9.53 & 8.83 \\
\hline$Q_{m}$ & 568 & 764 \\
\hline
\end{tabular}

about $300{ }^{\circ} \mathrm{C}$ (Fig. 5). For $1 \mathrm{kHz}$ frequency of the measurement field they are lower than 0.15. Above temperature $300{ }^{\circ} \mathrm{C}$ there is a significant increase in the dielectric losses connected with an increase in electric conductivity with high temperatures.

The PSZTC ceramics does not have very high values of the piezoelectric parameters $\left(d_{31}, g_{31}, k_{p}, k_{31}\right)$, but it shows high stability of a relative change of the resonance frequency $\Delta f_{r} / f_{r}$, and at the same time high stability of its parameters (Fig. 6), a slight increase in the value of the relative frequency change of the resonance stability $\Delta f_{r} / f_{r}$ (a decrease in the resonance frequency stability $f_{r}$ ), with a temperature increase. However in the whole measurement area the PSZTC ceramics has very low $\Delta f_{r} / f_{r}$ values. For the PSZTC ceramics polarized by the low temperature method the values of resonance stability $\Delta f_{r} / f_{r}$ do not exceed 0.0022 , whereas for the ceramics polarized by the high temperature method the values

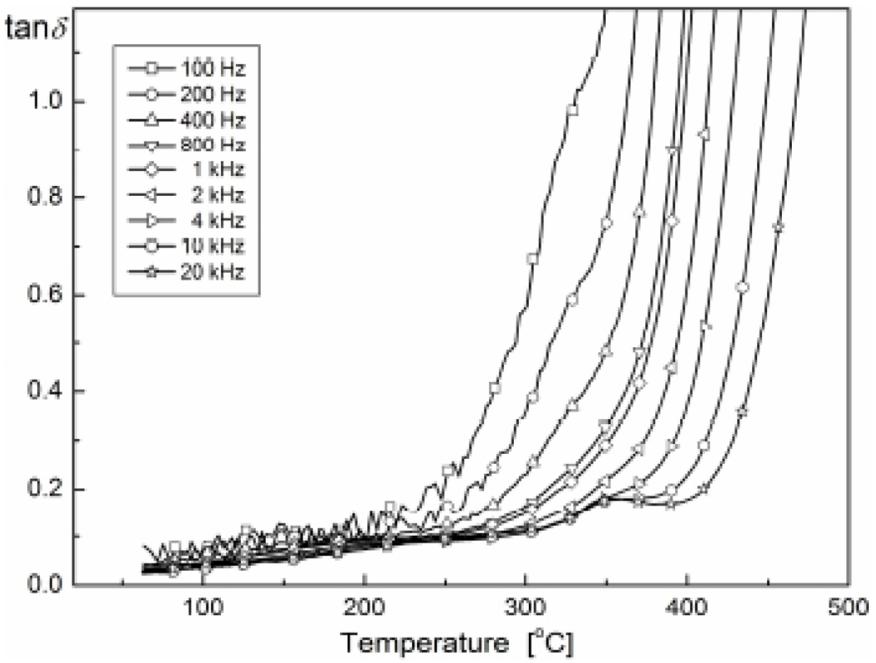

Fig. 5. Plot of dependences of a tangent of the dielectric loss angle in the temperature function for a cooling cycle for the PSZTC ceramics.

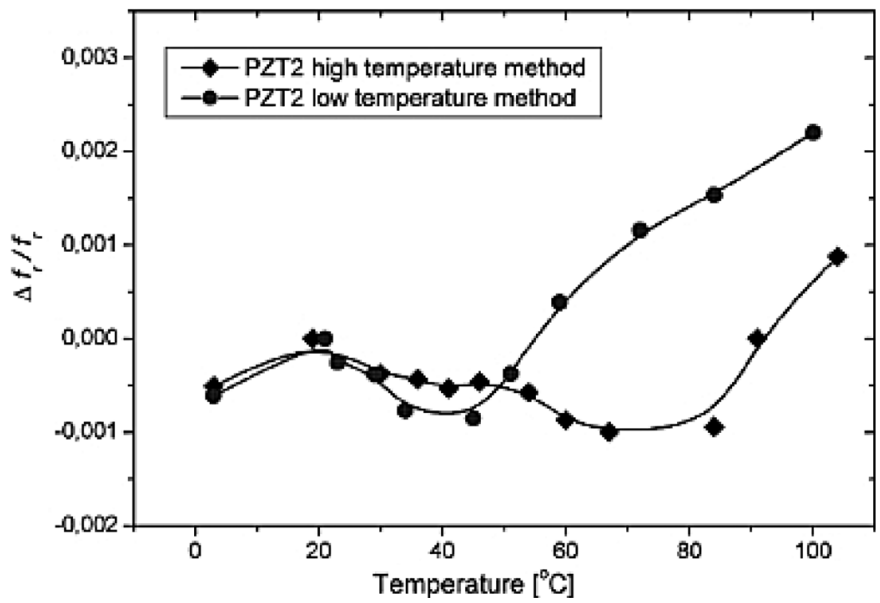

Fig. 6. Dependences of relative stability of the resonance frequency in the temperature function for the PSZTC ceramics polarized by high and low temperature methods.

of resonance stability are lower than 0.001 . The conducted examinations of the temperature stability of the piezoelectric parameters of the PSZTC ceramics confirm its high ferroelectric hardness what is manifested by high stability of resonance frequency, and also its other piezoelectric parameters.

\section{Conclusions}

This paper presents the results of research of successfully received multicomponent solid solutions PZT type with the following chemical composition: $\mathrm{Pb}_{0.94} \mathrm{Sr}_{0.06}\left(\mathrm{Zr}_{0.50} \mathrm{Ti}_{0.50}\right)_{0.99} \mathrm{Cr}_{0.01} \mathrm{O}_{3} \quad$ (PSZTC). Obtained results show that PSZTC samples are characterized by the good microstructure with small grains, high values of dielectric permittivity as well as low values of dielectric losses. 
The PSZTC ceramics has the mean value of piezoelectric parameters $\left(d_{31}, g_{31}, k_{p}, k_{31}\right)$, however this material shows high stability of a relative change of the resonance frequency $\Delta f_{r} / f_{r}$, and good stability of piezoelectric parameters. The conducted examinations of the temperature stability piezoelectric parameters of the PSZTC ceramics confirm that this material show high ferroelectric hardness, that is, high resistance to external factors such as external field, stress, etc.

Materials with such properties may be used to the construction of the piezoelectric elements of micromechatronic subassemblies and systems.

We are grateful for the assistance of Anna Latkiewicz (Laboratory of FE Scanning Microscopy and Microanalysis, Institute of Geological Sciences, Jagiellonian University, Krakow, Poland) for her help with the SEM pictures and XRD measurements.

\section{References}

1. K. Uchino, J.R. Giniewicz, Micromechatronics (Marcel Dekker, New York, 2003)

2. H. Schmid, J. Phys.: Condens. Matter 20, 434201 (2008)

3. E. Nogas-Ćwikiel, Arch. Metal. Mater. 56, 1065 (2011)
4. R. Zachariasz, A. Zarycka, J. Ilczuk, Mater. Sci. Poland 25, $781(2007)$

5. M. Adamczyk, Z. Ujma, L. Szymczak, A. Soszynski, J. Koperski, Mater. Sci. Eng. B 136, 170 (2007)

6. D. Bochenek, R. Zachariasz, Arch. Metal. Mater. 54, 895 (2009)

7. So-Yeon Yoo, Jong-Yoon Ha, Seok-Jin Yoon, Ji-Won Choi, J. Eur. Ceram. Soc. 33, 1769 (2013)

8. D. Bochenek, R. Skulski, P. Wawrzała, D. Brzezińska, J. Alloys Compd. 509, 5356 (2011)

9. Phan Dinh Gio, Le Dai Vuong, Ho Thi Thanh Ho, J. Mater. Sci. Chem. Eng. 2, 20 (2014)

10. R. Zachariasz, D. Bochenek, K. Dziadosz, J. Dudek, J. Ilczuk, Arch. Metal. Mater. 56, 1217 (2011)

11. R. Sitko, B. Zawisza, J. Jurczyk, D. Bochenek, M. Płońska, Microchimica Acta 144, 9 (2004)

12. D. Bochenek, R. Zachariasz, Arch. Metal. Mater. 54, 903 (2009)

13. V.S. Postnikov, V.S. Pavlov, S.K. Turkov, J. Phys. Chem. Solids 31, 1785 (1970)

Open Access This is an open access article distributed under the terms of the Creative Commons Attribution License (http://creativecommons.org/licenses/by/4.0), which permits unrestricted use, distribution, and reproduction in any medium, provided the original work is properly cited. 